Corrigendum

\title{
Corrigendum to "Fracture Risk in Type 2 Diabetes: Current Perspectives and Gender Differences"
}

\author{
Giuseppina T. Russo, Annalisa Giandalia, Elisabetta L. Romeo, Nunziata Morabito, \\ Marco Muscianisi, Maria Concetta Ruffo, Antonino Catalano, and Domenico Cucinotta
}

Department of Clinical and Experimental Medicine, University of Messina, Messina, Italy

Correspondence should be addressed to Giuseppina T. Russo; giuseppina.russo@unime.it

Received 23 May 2017; Accepted 31 May 2017; Published 16 July 2017

Copyright (C) 2017 Giuseppina T. Russo et al. This is an open access article distributed under the Creative Commons Attribution License, which permits unrestricted use, distribution, and reproduction in any medium, provided the original work is properly cited.

In the article titled "Fracture Risk in Type 2 Diabetes: Current Perspectives and Gender Differences" [1], with regard to the FRAX ${ }^{\circledR}$ tool, it has been reported that "Among the different tools to assess fracture risk, the WHO fracture risk assessment (FRAX) is a computer based algorithm (http://www.shef.ac.uk/FRAX/) primarily intended for use in primary care $[56,57] . "$ We point out that the metabolic bone disease unit at the University of Sheffield that developed FRAX was a WHO Collaborating Centre from 1991 to 2010, but the World Health Organization (WHO) did not develop, test, or endorse the FRAX tool or its recommendations [2]. Additionally, the name of the fourth author was given incorrectly as Morabito Nunziata. The author's name should have been written as Nunziata Morabito. The revised authors' list is shown above.

\section{References}

[1] G. T. Russo, A. Giandalia, E. L. Romeo et al., "Fracture risk in type 2 diabetes: current perspectives and gender differences," International Journal of Endocrinology, vol. 2016, Article ID 1615735, 11 pages, 2016.

[2] N. Ford, S. L. Norris, and S. R. Hill, “Clarifying WHO's position on the FRAX $^{\circledR}$ tool for fracture prediction," Bulletin of the World Health Organization, vol. 94, no. 12, p. 862, 2016. 


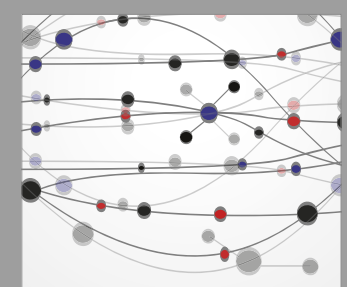

The Scientific World Journal
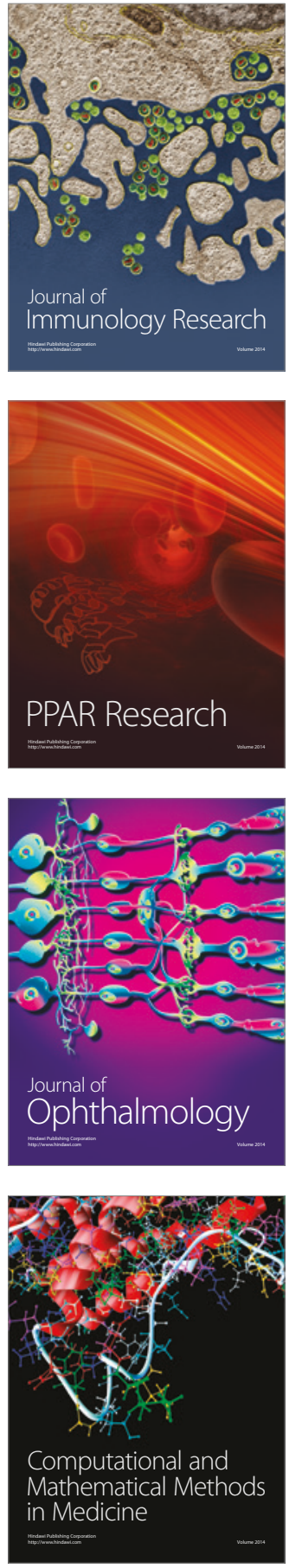

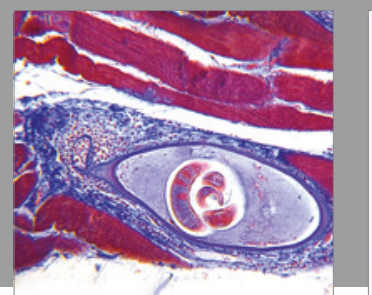

Gastroenterology Research and Practice
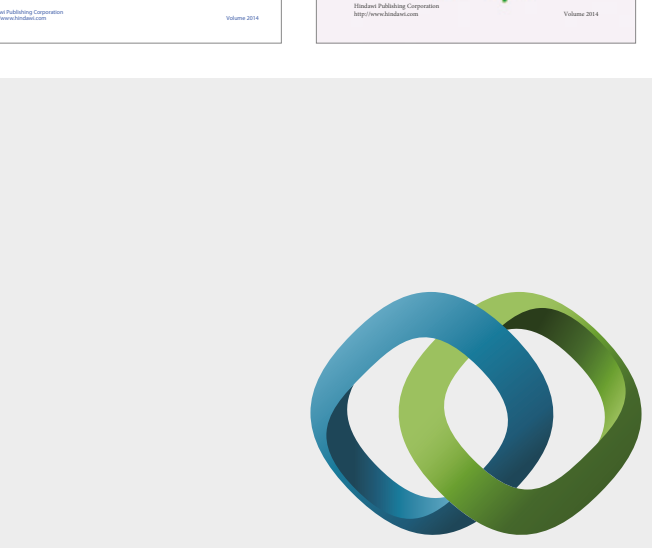

\section{Hindawi}

Submit your manuscripts at

https://www.hindawi.com
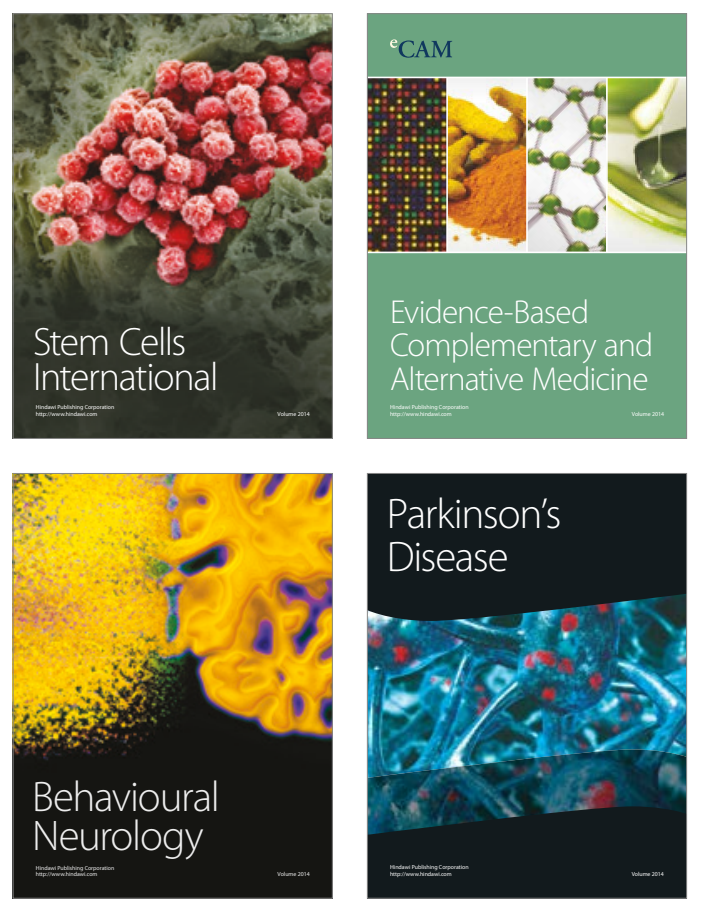
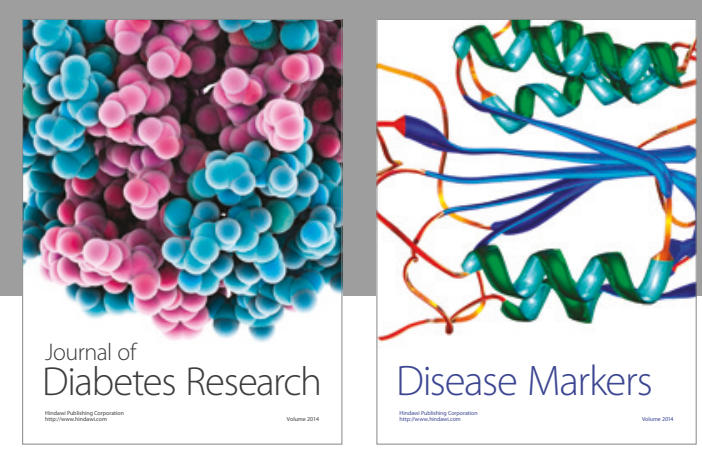

Disease Markers
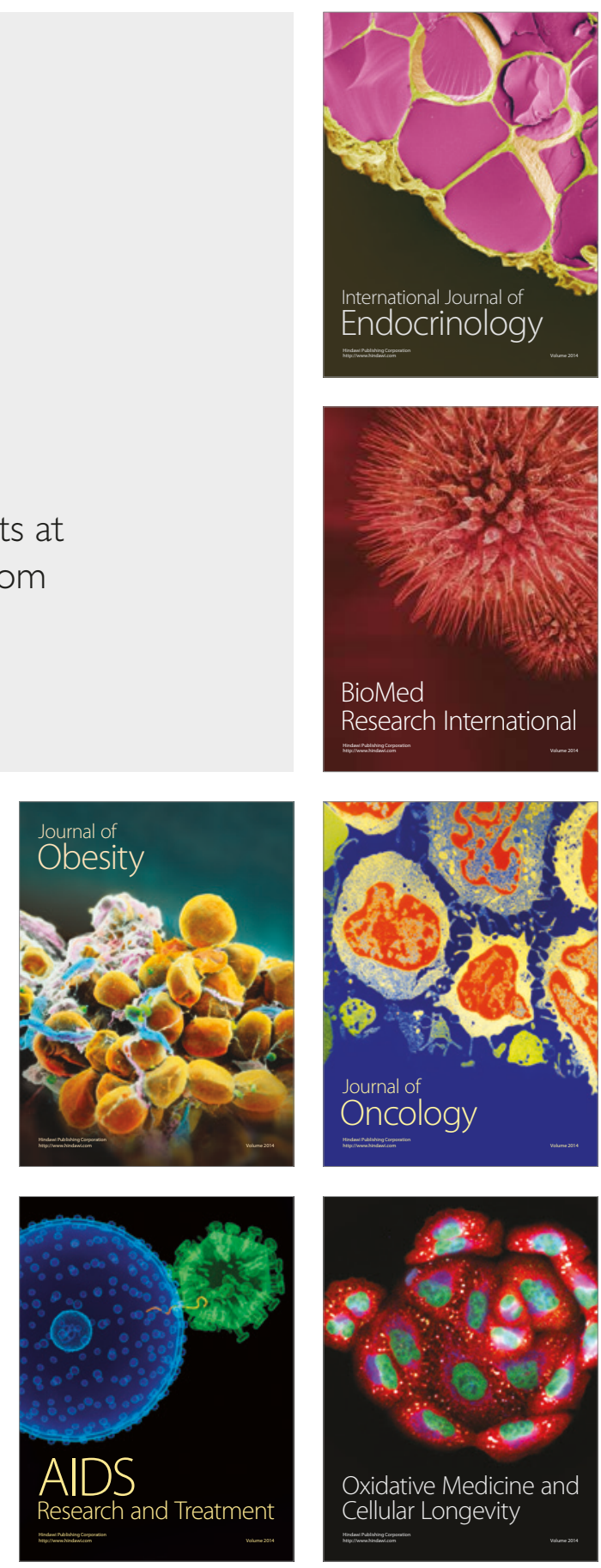